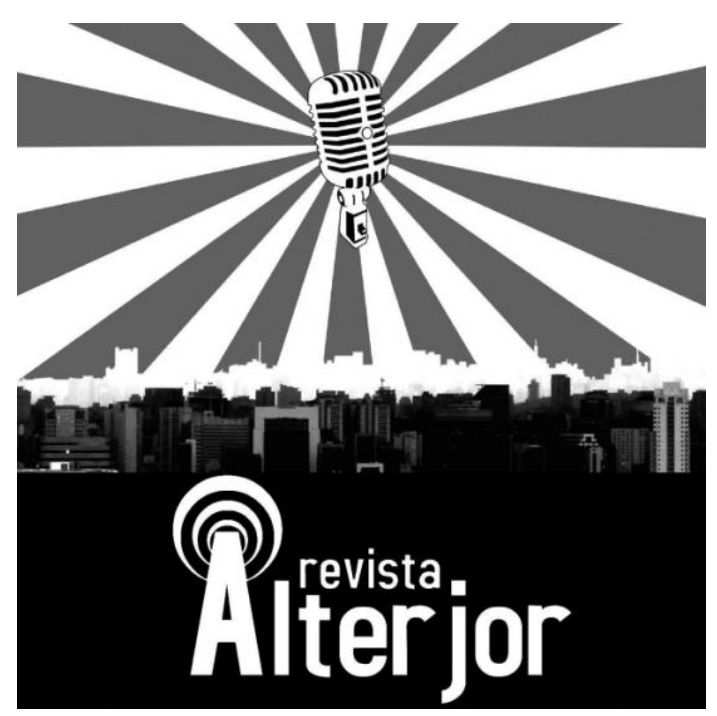

DOSSIê: "Comunicação nas Periferias"

\title{
A FORÇA SOLIDÁRIA DO JORNALISMO DAS PERIFERIAS
}

\author{
Ethel Shiraishi Pereira ${ }^{1}$
}

RESUMO: Para melhor compreender quem são os jornalistas que atuam em veículo de comunicação cujas pautas estão centradas nos bairros periféricos das cidades da Região Metropolitana de São Paulo, Mara Rovida pesquisa o universo desses jornalistas e produz seu mais recente livro, "Jornalismo das periferias: o diálogo social solidário nas bordas urbanas". Entre referenciais teóricos e relatos extraídos de seu diário de campo, produzido ao longo de 3 anos, o leitor é convidado a conhecer o jornalismo praticado nas bordas urbanas, desde a descoberta do tema de pesquisa, passando pela caracterização da periferia pelos periféricos; discutindo o jornalismo das periferias; conhecendo os jornalistas das periferias; até seu ponto de chegada.

PALAVRAS-CHAVE: Jornalistas das periferias. Periferias urbanas. Diálogo social. Coletivos.

ABSTRACT: To better understand who are the journalists acting at news media centered in the peripheral neighborhoods from the cities of the Greater São Paulo, Mara Rovida researches their universe and delivers her most recent book, "Jornalismo das periferias: o diálogo social solidário nas bordas urbanas". Among theoretical references and reports extracted from her field journal, produced throughout three years, the reader is invited to know the journalism practiced at the urban edges, from the discovering of the research's theme, passing through the characterization of the periphery by the peripheral journalists; discussing the peripheral journalism; getting to know the peripheral journalists; to her point of arrival.

KEYWORDS: Peripheral journalist. Urban peripheries. Social dialogue. Collectives.

\footnotetext{
${ }^{1}$ Ethel Shiraishi Pereira é professora de Relações Públicas e membro do Grupo de Pesquisa no CNPQ Comunicação na Sociedade do Espetáculo da Cásper Líbero. Também atua como docente do MBA em Gastronomia e Gestão de Eventos e da Pós-Graduação em Comunicação Corporativa da Universidade Anhembi Morumbi e do Curso de Marketing Político e Propaganda Eleitoral da ECA-USP. E-mail: ethel.pereira@gmail.com
}

Revista ALTERJOR

Grupo de Estudos Alterjor: Jornalismo Popular e Alternativo (ECA-USP)

Ano 10 Volume ol Edição 23 Janeiro-Julho de 2021

Avenida Professor Lúcio Martins Rodrig̉ues, 443, Cidade Universitária, São Paulo, CEP: 05508-020 


\section{RESENHA}

Publicado em junho de 2020 pela Editora CRV, o livro "Jornalismo das periferias: o diálogo social solidário nas bordas urbanas" é fruto de uma pesquisa desenvolvida por Mara Rovida, professora do curso de jornalismo e da pós-graduação em Comunicação e Cultura da Universidade de Sorocaba (Uniso), com jornalistas que atuam em bairros periféricos das cidades da Região Metropolitana de São Paulo (RMSP). Embora seja um trabalho acadêmico, Mara faz uso de uma narrativa que conjuga as experiências de seus entrevistados com a sustentação teórica necessária para que possamos compreender quem são esses jornalistas que atuam em veículos especializados em retratar pautas de lugares periféricos, a partir do olhar de quem vive nesses territórios.

Estruturado em cinco capítulos: a descoberta; a periferia pelos periféricos; jornalismo das periferias; os jornalistas das periferias e ponto de chegada, o livro conta, ainda, com o posfácio que vale a leitura pois é uma verdadeira aula escrita pela pesquisadora Cremilda Medina, professora titular sênior da Escola de Comunicações e Artes da Universidade de São Paulo. Mas o que dizer sobre uma obra que possui um posfácio escrito por Cremilda Medina? Me sinto pequena e incapaz de contribuir pois o diálogo que Cremilda estabelece com a Mara é algo que entra na essência da teoria e da técnica jornalística. É conversa de gente grande e nesse caso, me limito a apenas ouvir e aprender.

Mas o livro me toca de maneira muito particular, aguçou minha memória afetiva e me fez refletir sobre um período da minha vida. Por isso decidi escrever algumas impressões. O período a que me refiro é aquele que começa com a morte de meu pai em 1980, e provoca nossa mudança de São Paulo para Guarulhos, até o momento em que me caso e volto a morar em São Paulo. Vivi um pouco mais de uma década em Guarulhos, cidade da Grande São Paulo, hoje considerado o segundo maior município do Estado de São Paulo por número de habitantes. Mas na época, fomos morar num bairro que, embora próximo ao centro, ainda era considerado fora da cidade. Nem todas 


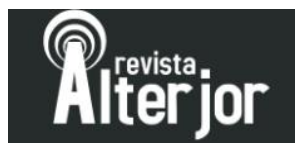

as ruas eram asfaltadas ou tinham iluminação pública. O transporte coletivo era algo raro e ir à São Paulo estava fora das nossas possibilidades. Nunca achei que sentiria saudades de lá, mas outro dia, assistindo ao Bom Dia São Paulo, o repórter percorreu a Rua Dom Pedro, hoje calçadão, de longe revi a igreja matriz... Bateu saudades e me lembrei das vezes em que íamos tomar sorvete na rua lateral da igreja e depois esperávamos o nosso ônibus no ponto lotado da matriz... às vezes de tanto esperar, decidíamos voltar para casa a pé. Passei minha adolescência em Guarulhos e o livro me fez lembrar que quando comento com meus alunos que estudei no Conselheiro Crispiniano de Guarulhos, para muitos isso não quer dizer nada, mas de vez em quando, um rosto se ilumina e vejo que a pessoa se encoraja a levantar a mão e dizer que também é de Guarulhos. Raro pois sou professora de escola elitizada. Mas também trabalhei em São Miguel Paulista e sei que para aqueles alunos, ter estudado em Guarulhos era um privilégio.

Mara escreve fácil, é muito bom ler o seu texto. A narrativa demonstra organização em sua pesquisa. É o relato de um diário criado com detalhes e ela não tem vergonha de expor cada etapa de sua pesquisa. É como se estivéssemos entrando na cabeça da Mara e conhecendo como funciona o seu raciocínio. A autora utiliza a abordagem etnográfica como técnica para sustentar a pesquisa que é feita de forma coletiva, a partir da participação em um evento, somada à sua experiência docente, estudos e autores de referência e novas descobertas. Ouvir as fontes e seguir intuitivamente as indicações oferecidas por aquele que vive o objeto pesquisado é um dos métodos utilizados.

Percebo que os dilemas jornalísticos são parecidos com os das relações públicas. Creio que se tratam de dilemas da comunicação, de uma forma mais ampla, pois trabalhar a comunicação comunitária tem suas peculiaridades seja no jornalismo, seja nas relações públicas, na publicidade, no radialismo ou no cinema. Pensar a comunicação fora do jogo de interesses das grandes corporações torna-se, talvez, um desafio para todos nós.

O ponto do livro, mais tocante para mim é o 4.1 Um esboço de perfil coletivo. Aqui, Mara nos mostra que possui mais do que vocação para contar histórias, ela tem o talento

\footnotetext{
Revista ALTERJOR

Grupo de Estudos Alterjor:Jornalismo Popular e Alternativo (ECA-USP)

Ano 10 Volume ol Edição $23 \quad$ Janeiro-Junho de 2021

Avenida Professor Lúcio Martins Rodriģues, 443, Cidade Universitária, São Paulo, CEP: 05508-020
} 


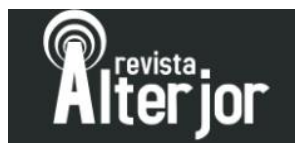

para captar os aspectos mais profundos das experiências de vida de seus entrevistados. Ao mesmo tempo que torna particular, porque parte das narrativas de cada um de seus personagens, também amplia a descrição do perfil a ponto de torná-lo universal. E mais do que o perfil do jornalista da periferia, Mara descreve o perfil do jovem de periferia que, independente da profissão que escolhe, passa por situações e sentimentos muito semelhantes aos descritos em seu texto. Com a expectativa de que o livro toque cada leitor de uma maneira muito particular, tomo a liberdade de compartilhar os pontos com os quais me identifiquei:

a) A ampliação das percepções sobre "a casa, a rua, o bairro, a cidade, a vida" - aos poucos a compreensão sobre o nosso espaço vai se transformando a partir das experiências que vivenciamos, das leituras que fazemos, das trocas que nos permitimos ou somos expostos. O que num primeiro momento é encarado como um limitador, um entrave, aos poucos pode se transformar em um elemento de formação de uma identidade, mesmo que não tenhamos percepção a respeito.

b) A ideia de que o melhor investimento que se pode fazer a uma criança, a um filho é o acesso à educação. Aquela ideia de que ninguém pode nos tirar o conhecimento é uma grande verdade para muitas famílias pobres e para os jovens que se agarram aos estudos para tentar melhorar de vida.

c) O sonho de uma formação técnica, profissionalizante, para garantia de um emprego e, com isso, a possibilidade de ajudar com as despesas da casa. No meu caso, a teimosia me afastou de uma escola técnica e me colocou nos braços da comunicação. Não me arrependo, mas me questiono se não deveria ter sido um pouco mais ousada.

d) A questão do CEP - um fato. Tenho relatos de alunos que colocavam em seus currículos o CEP de parentes ou amigos que moravam em bairros mais centrais para garantir, pelo menos, uma entrevista de emprego. No meu caso, moradora de Guarulhos, quando fui selecionada para estagiar em uma entidade de classe em Moema (bairro nobre de São Paulo), fui questionada se a distância entre a minha residência e o local de trabalho não seria um problema para justificar eventuais atrasos... Lógico que dei minha palavra de que isso não aconteceria, 


\section{Preitior}

mas em troca precisei, muitas vezes, me arriscar a viajar pendurada na porta do ônibus, pelo lado de fora, pois se não fosse assim, certamente perderia o horário de entrada no trabalho. Um percurso que atravessava toda Av. Guarulhos, Via Dutra, Marginal Tietê, depois várias estações da linha azul do Metrô e mais um ônibus até chegar ao destino. Confesso que não me recordo quanto tempo eu "perdia" no trajeto, talvez seja um bloqueio em minha memória - na época não tínhamos os celulares e os recursos tecnológicos de hoje em dia, a ponto de permitir ouvir notícias e podcasts e, com isso, me manter "produtiva" enquanto me deslocava. Ou, hoje pensando por outro lado, quanto tempo eu "ganhava" ouvindo minhas músicas num walkman, algo pra lá de chique na época!

Fico aqui pensando. Sim, fui por um tempo uma jovem da periferia. E isso não se transformou em um projeto profissional, como no caso dos jornalistas retratados no livro da Mara. Na época em que estudei, não tive exemplos ou articulações com outros jovens que, como eu, vinham da periferia e puderam perceber que o fazer profissional naquele espaço poderia ser algo transformador. Que bom que estes coletivos estejam se articulando, que bom que Mara e outros pesquisadores estejam olhando para este universo.

\section{REFERÊNCIA}

ROVIDA, Mara. Jornalismo das periferias: o diálogo social nas bordas urbanas. Curitiba: CRV, 2020. 